Portland State University

PDXScholar

Curriculum and Instruction Faculty Publications

and Presentations

Curriculum and Instruction

$11-1-2018$

\title{
The Ouroboros of Rubrics: A Conundrum, a Case, and a Call
}

Anita Bright

Portland State University, anita.bright@pdx.edu

Follow this and additional works at: https://pdxscholar.library.pdx.edu/ci_fac

Part of the Curriculum and Instruction Commons

Let us know how access to this document benefits you.

\section{Citation Details}

Bright, A. (2018). The ouroboros of rubrics: A conundrum, a case, and a call. Power and Education, 10(3), 333-338. https://doi.org/10.1177/1757743818769428

This Post-Print is brought to you for free and open access. It has been accepted for inclusion in Curriculum and Instruction Faculty Publications and Presentations by an authorized administrator of PDXScholar. Please contact us if we can make this document more accessible: pdxscholar@pdx.edu. 


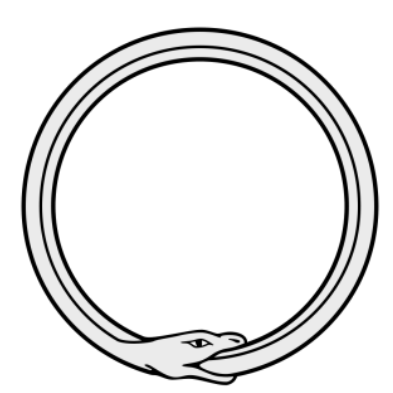

\section{The Ouroboros of Rubrics: A Conundrum, A Case, and A Call}

\section{The conundrum}

How can we, as educators, simultaneously provide our students with unambiguous instructions for their assignments while at the same time providing luxurious and loving opportunities for creative interpretations of the work we engage in? When it comes to assignments, how can we remove the expectation that students read our minds, while at the same time allow for unique and individual responses to prompts? How can we provide guideposts without limiting the paths students may walk? This is our grapple, our affliction, our bane. And more specifically, how can we as instructors, in recognition of our moral and ethical responsibilities as a part of our academic integrity, use a rigid rubric to evaluate the work of our doctoral students? Enter the ouroboros, the serpent devouring herself, speaking to the circular tensions in this conundrum. How can we be entirely transparent about expectations while at the same time allowing for students to independently interpret what the work is intended to be?

\section{The context}

As a committed educator, I am the professor in a graduate program (at the master's and doctorate levels), with students who are curious and wise and eager, each 
hungry in different ways for the academic paths they're envisioning and constructing for themselves. All cluster their interests and passions beneath the umbrella of our department, Curriculum and Instruction, but with uniquely tailored points of focus for their research. A student may focus on the role of play in early childhood settings; the historical marginalization of teachers of color; or styles of teacher-family interactions that best serve the needs of students. Each voice adds a new layer, a new angle, a new nuance to the collective conversation, challenging, strengthening, and deepening our understandings on a kaleidoscope of topics, speaking to the ideal Vygotsky (1966) explained as, "Becom[ing] ourselves through others" (p.43).

As a professor, I do not hold unassailable expertise on the topics these students have selected. Rather, I have familiarity with the field of curriculum and instruction a whole, and familiarity with the process of earning a doctorate, or what Shulman (1986) would term pedagogical content knowedge (p.9). As professors and students working together, we live through these cycles of the ouroboros, again, the serpent eating her own tail, cycling into and out of knowing, wondering, wavering. I have experience in scholarly writing, and in research, and in what it means and what it takes to earn a doctorate. As such, we together form a community of practice (Lave \& Wenger, 1991), learn in community, and labor in community with our students and with one another, spinning together, in Anzaldúan (1987) terms, tapestries (metaphorical, of course) of new truths and questions, threaded with both poetic and mundane ideas, fluidly moving between insights from the Buddha (on our syllabus) and insights from Kincheloe (in our textbooks). We press forward, metaphorical lamps in hand, squinting ahead into fresh territories and fixing our ears towards new tones, learning with and learning from one 
another through the process. This whirled richness, these voices of our students, are what enliven and motivate and sustain us in the work.

The work.

The work is here, in the "the academy." This work is both of the academy and in the academy, with each preposition acknowledging different facets of the same gem. In collaboration with my peers and students, we work within the confines of the structures, while at the same time occasionally jamming our elbows against the most rigid parts of the framework itself, mindful of the potential for life-changing consequences (such as failing to pass muster with institutional review boards, failing to successfully complete the dissertation, or injuring relationships with others).

\section{The culminating projects}

Each of the students in our graduate programs over the last few years have approached key academic milestones of various forms, sometimes as a comprehensive exam, or a dissertation proposal, or a final action research project. At our institution, as is the case in many institutes of higher education in the US, these milestones often take the form of a lengthy paper, with an accompanying oral presentation--- that, in our case, is bounded by a one-size-fits-all rubric, universally applied, whether the student is writing about accommodations in special education, policies of school suspension, or literacy strategies for emergent bilinguals. In our programs, we use one of several "universal" rubrics intended to evaluate work which may be focused on the role of faith identity in teachers, or the use of technology as a curricular focus, or the ways bias may cloud the views of school librarians.

One rubric for each type of assignment. The rubric for each type of assignment. 
The rubric, intended to both guide and evaluate. The rubric, a graciously constructed roadmap to guide the way, or a clinically precise demand to conform? The rubric: a student's savior, or a student's bane? This is not to suggest that such clear binaries—savior/ bane-actually exist. Might a rubric be both, depending on the angle from which one views it?

Rubrics, defined by Popham (1997) as "a scoring guide used to evaluate the quality of students' constructed responses," (p. 52), are seen as "writing assessment's current sacred cow because they provide the appearance of objectivity and standardization" (Wilson, 2007, p. 66). While emphasizing this concept of objectivity and "fairness," rubrics are also marketed to educators as a way to "save time" while grading. Critical of this self-serving rationale, Kohn's (2006) response to this notion of "saving time" was that, "the best teachers would react to that selling point with skepticism, if not disdain" (p. 12). As Zinn (as cited on goodreads.com, 2016), expressed,

I'm worried that students will take their obedient place in society and look to become successful cogs in the wheel - let the wheel spin them around as it wants without taking a look at what they're doing. I'm concerned that students not become passive acceptors of the official doctrine that's handed down to them from the White House, the media, textbooks, teachers and preachers.

Like Zinn, I, too, fear my students—not to mention myself—might take our obedient place in society, quietly accepting what has been handed down.

\section{The case}


The vividness of the tensions in the potential for bane with the use of rubrics has taken shape during the last few years of their use in my professional practice as a professor. As various students have spoken to the nuances of their chosen topics, it is clear that some students have, in many ways, been strongly guided, supported, and buoyed by the lift and loft provided by the rubric. Others, however, were lashed to the masts of the ship that was the rubric, working so hard to speak to each of the elements in that gridded, "epistemological cage" (D'Ambrosio, 2015, p. 23) through the voice of their research passions.

Many students have been entirely at home as they open their presentations, just as the rubric outlines, by identifying their chosen "problem of practice" and recognizing its boundaries. In lockstep conformity with the boxes on the rubric, they describe the context, they validate that the problem exists, and they define their terms with clarity and deep insight. They speak with authority to the educational significance of the problem, invoking relevant theories to frame and articulate their work. The rubric often works well at this point, providing a tensile structure upon which students can unfurl their insights, their passions, their wonderings.

And then, often, there emerges some part of the rubric that requires students to focus on something, some element, not entirely (or not even tangentially) linked to their curiosity, their focus, their topic as a whole. The rubric demands something unanticipated by the author of the tool, something not connected to reality lived by the student-author. The fit then moves from tightly-mapped to awkwardly matched. As faculty, we are using a very specific organizational structure-one not chosen nor designed by the students themselves - to evaluate the work the students themselves 
have decided upon. Narrative tensions arise in navigating how best to fit any and all topics into the structures defined by the rubric, a priori.

In considering the rubric itself, we, as scholars, are aware that the very structure of the rubric is a representation of a machine-like system, and that while using it to evaluate student work, we may be engaging in a highly impositional act, with an overt directive to conform. Suddenly, Popham's (1997) declaration that "the vast majority of rubrics are instructionally fraudulent" (p. 74) takes on new urgency. In what ways might we, as faculty, be participant in - or purveyors of-a kind of instructionally fraudulent act? Or rather, are we providing clear guidance and useful structures?

How, then, might we be colluding in a form of broad and bold acculturation? Some may argue this is entirely the point of a graduate program - to elicit conformity to the master script, re-casting our students in our own image. The creators of the rubrics themselves most surely see rubrics as gift-like, touting the benefits of rubrics for their transparency, while downplaying (or perhaps outright denying) any elements of conformity built into them. Points about transparency are entirely vivid and valid, but... what about the nagging problem with conformity? Does this troubling aspect somehow cancel out because the transparency is so useful?

In indignant support of rubrics, some have asked, "How, then, do you dismantle the master's house?" strongly suggesting that rubrics provide access to the master's house, serving as "the tools" with which to dismantle said house, as if the work of scholarly research could possibly be so discrete, so bounded, so formulaic or so technical. 
Clearly seeking to reference the work of Audre Lorde, and in particular, Lorde's (1984) quote about the master's tools, those posing this question ("How, then, do you dismantle the master's house?") have somehow reshaped the quote in their own thinking, and as a result, re-cast the meaning to align their own genuinely benevolent beliefs and intentions about rubrics. What Lorde actually wrote was far more critical of the institutions of power. Lorde (1984) wrote:

Those of us who stand outside the circle of this society's definition of acceptable women; those of us who have been forged in the crucibles of difference -- those of us who are poor, who are lesbians, who are Black, who are older -- know that survival is not an academic skill. It is learning how to take our differences and make them strengths. For the master's tools will never dismantle the master's house. They may allow us temporarily to beat him at his own game, but they will never enable us to bring about genuine change. And this fact is only threatening to those women who still define the master's house as their only source of support. (p. 112)

Many students at my institution (just like students across the US) speak from the place Lorde described--outside the circle. At the same time, pro-rubric educators animate the idea that "many of the tenets of positivism are so embedded within Western culture, academia, and the world of education in particular that they are often invisible to researchers and those who consume their research" (Kincheloe \& Tobin, 2009, p. 513). Similarly, just as Said (2003) explained, "Every empire, however, tells itself and the world that it is unlike all other empires, that its mission is not to plunder and control but to educate and liberate" (p. 20), the pro-rubric community attempts to put forward the 
same idea-- that the rubric itself is not a prison, but rather, a gift to our students, serving to grant access.

So herein I return to my particular bane with regard to rubrics: As an institution, we want to both provide access to the "keys to the kingdom," while at the same time we want to disrupt and change the kingdom itself. Speaking to this tension, Kohn (2006) points out, "There's a big difference between thinking about the content of a story you're reading ... and thinking about your own proficiency at reading" (p. 13-14). How might we, as educators who seek to practice radical love, which West (2015) describes as something which "a radical humility and radical integrity" (p. 3), simultaneously provide loving and structured support for our students while at the same time knowing that access to the academy, in it's current state, requires some degree of conformity and acculturation?

\section{The conclusion (of sorts), and a call}

So where does this leave us, as scholars who may have already gained access to the academy, and not without loss, wound, or compromise, but with the deep desire to disrupt and change the oppressive and restrictive structures in place that serve to bar, to limit, to deny others seeking access? Perhaps we're still animating the ouroboros, devouring our own tails through infinite cycles, using the rubric (because it's institutionally required) while simultaneously knowing it's a limited and constrictive construct in so many, many ways. We've both paid the ferryman, maybe Vasudeva or perhaps Charon, for safe passage across the river into the land of academe, but find ourselves wondering if now we, ourselves, have somehow become the very ferryman ourselves. As Kress (2011) wonders, 
For scholars such as myself who have been immersed in Western culture and Western notions of research and science, colonialism and positivism have been normalized to the point where they feel commonsensical and are often hidden from me even as I might embody and enact these norms. (p. 270)

Do we compromise standards and quality and rigor, as defined by some communal (but external) experts and permit our students to create works that somehow fall outside of what is considered to be "scholarly" by these measures? Do we cede to the need for ethical inter-rater reliability to ensure all students have equitable chances of passing their high-stakes comprehensive exams? Or do we support our students in growing along their own trajectories, trusting that they will succeed in this process, allowing them to carve new paths we, ourselves, have not yet come to recognize or understand? 


\section{References}

Anzaldúa, G. E. (1987). Borderlands/La Frontera: The New Mestiza. San Francisco, CA: Aunt Lute Books.

D’Ambrosio, U. (2015). From Mathematics Education and Society to Mathematics Education and a sustainable civilization: a threat, an appeal, and a proposal. In S. Mukhopadhyay \& B. Greer, (Eds.), Proceedings of the Eighth International Mathematics Education and Society Conference, 8 (19-30). Portland, OR: Ooligan Press, Portland State University.

Kincheloe, J. L., \& Tobin, K. (2009). The much exaggerated death of positivism. Cultural Studies of Science Education, 4(3), 513-528.

Kohn, A. (2006). The trouble with rubrics. English journal, 95(4), 12-15.

Kress, T. M. (2011). Stepping out of the academic brew: Using critical research to break down hierarchies of knowledge production. International Journal of Qualitative Studies in Education, 24(3), 267-283.

Lave, J., \& Wenger, E. (1991). Situated learning: Legitimate peripheral participation. Cambridge university press.

Lorde, A. (1984) The Master's Tools Will Never Dismantle the Master's House. Sister Outsider: Essays and Speeches (110-114). Berkeley, CA: Crossing Press.

Popham, W. J. (1997). What's wrong-and what's right-with rubrics. Educational leadership, 55, 72-75.

Said, E. (2003). Blind Imperial Arrogance. Los Angeles Times, July, 20. 
Shulman, L. S. (1986). Those who understand: Knowledge growth in teaching. Educational researcher, 15(2), 4-14.

Vygotsky, L.S. (1966) Development of higher mental functions. In A.N. Leontyev, A.R. Luria and A. Smirnov (Eds.) Psychological Research in the USSR. Moscow: Progress Publishers.

West, C. (2015). The Radical King. Boston, MA: Beacon Press

Wilson, M. (2007). Why I won't be using rubrics to respond to students' writing. English Journal, 62-66.

Zinn, H. (2016). Howard Zinn > Quotes. Retrieved from http://www.goodreads.com/quotes/17916-i-m-worried-that-students-will-taketheir-obedient-place-in 